\title{
Queensland Storm Surge Forecasting Model Design Using Sensitivity Analysis
}

\author{
Gaelle Faivre $^{\mathrm{a}}$, Joanna Burston ${ }^{\mathrm{b}}$, Dan Ware ${ }^{\mathrm{a}}$ and Rodger Tomlinson ${ }^{\mathrm{a}}$ \\ ${ }^{a}$ Griffith Centre for Coastal Management, Griffith University, Southport, QLD 4215 Australia. \\ ${ }^{b}$ Baird Australia, 309 Kent St Sydney NSW 2000 \\ Email: Email:g.faivre@griffith.edu.au
}

\begin{abstract}
Storm surge is a destructive and life threatening natural hazard associated with tropical cyclone (TC) events with the Queensland (Qld) coastline being particularly vulnerable. In a disaster management context, understanding the full range of possible scenarios that may arise from an impending event is critical for informed evacuation decision making. Tropical cyclones are difficult to forecast in terms of track and intensity, and storm surge magnitude is highly sensitive to the specific direction and location of peak cyclonic wind forcing in interaction with the local bathymetry. Here we investigate the optimal design of the next-generation storm surge forecasting system using a sensitivity analysis approach.
\end{abstract}

The storm surge forecasting system, QSurge consists of a web-based probabilistic hazard mapping interface drawing from a large database of pre-simulated events. The aim of this paper is identify the appropriate increments of various tropical cyclone parameters necessary to capture the full range of possible storm surge outcomes whilst minimising computational run time. Sensitivity modelling experiments were conducted, consisting of simulating a range of TC parameter values within a parametric wind field model and then simulating storm surge using the Coral Sea MIKE21 hydrodynamic model established for this study and implemented on high performance computing. Detailed analysis of the results was undertaken for the study sites of Cairns, Cardwell and Townsville in North Queensland, and used to determine the optimal range of values for the various cyclone parameters. The number of scenarios necessary to complete a full ensemble database for landfall locations between Cooktown and the Whitsundays was initially estimated as 2,165,240. This was reduced to a set of 664,335 scenarios using polynomial relationships between peak storm surge magnitude and TC parameters such as central pressure and radius of maximum winds. Such a simulation set is achievable using high performance computing and given the optimised run time of the numerical model.

Keywords: $\quad$ Storm surge, tropical cyclone, numerical modelling, sensitivity testing, optimisation 


\section{INTRODUCTION}

Griffith Centre for Coastal Management (GCCM)'s "Storm Surge Modelling for Emergency Response Management in Queensland" project is an initiative of the Queensland State Government to improve decision-making tools for emergency and disaster managers in the event of storm surge due to tropical cyclones. This pilot research study aims to test the capability of real-time storm surge inundation forecasting for Queensland and develop decision support products for storm tide risk from a forecasting perspective.

The storm surge forecasting system, QSurge, consists of a web-based probabilistic hazard mapping interface drawing from a large database of pre-simulated events. Storm surge is a highly non-linear phenomenon with many factors influencing its peak magnitude and spatial variability, including the cyclone angle of approach to land, forward speed, intensity, scale or extent of influence, the ocean bathymetry and the coastline shape, as well as interaction with other processes such as the astronomical tide, wave radiation stresses, and freshwater flooding.

The sensitivity analysis presented in this paper aims to identify the key cyclone parameters governing uncertainty in storm surge simulations, using a parametric wind field model and a 2D-depth integrated hydrodynamic model. A quantified understanding of these uncertainties will be used to define the required size of the underlying database of model runs supporting the QSurge tool.

The current database is a prototype version that only contains scenarios for one forward speed, one Radius of Maximum Wind and a range of angle of approach varying from 180 to 360 with 20 degrees increments. It would be needed to develop this database in optimizing the number of scenarios so as to expand the database.

The study site for the present study is limited to the Coral Sea margin along eastern coastline of Queensland, with a focus on North Queensland between Cooktown and the Whitsundays. The Coral Sea is an active area for tropical cyclone development, with a tropical monsoonal climate. Tropical cyclones can form in the Coral Sea and move in any direction, including offshore, moving landward, parallel to the coastline, or cutting across Cape York into the Gulf of Carpentaria. Based on analysis of the BOM's best track cyclone database an annual average of 4.1 tropical cyclones have affected the Queensland Tropical Cyclone Warning Centre Area of Responsibility (including the Gulf of Carpentaria) and 3.2 tropical cyclones per year have affected the Coral Sea between 10 and $28.2^{\circ} \mathrm{S}$ over the 1906 to 2014 period.

Section 2 will describe the experiment design of the sensitivity testing in which six tropical cyclone parameters are varied: (1) angle of approach, (2) forward speed, (3) landfall location/spacing, (4) cyclone intensity, (5) radius of maximum winds (RMW), and (6) inflow angle. Section 3 will present, results for each parameter, which will then be discussed in Section 5 to estimate the total number of scenarios needed to complete the database.

\section{METHOD}

\subsection{Experimental design}

The areas of interest are the northern Queensland towns of Cairns, Cardwell and Townsville as shown in Figure 1. These locations were selected for investigation given their critical importance for storm surge risk and also prior validation of the model for TCs Yasi and Larry affecting this area (Burston 2013). Comparison of the ACCESS-TC forecast and observed wind speed for TC Yasi (ACCESS data courtesy of Noel Davidson, BOM) for Cairns, Cardwell and Townsville has been reported in Burston (2014). Some of the specific assumptions and limitations associated with the cyclonic wind field have been discussed in Joanna et Al. (2014).

To capture the full scenario set, we aim to identify either a relationship or the discrete increment between adjacent values for each cyclone parameter required to minimise the difference in storm surge magnitude. An acceptable variation in peak storm surge magnitude between adjacent parameter values is defined as $0.3-0.5 \mathrm{~m}$, which is approximately the value of the storm surge

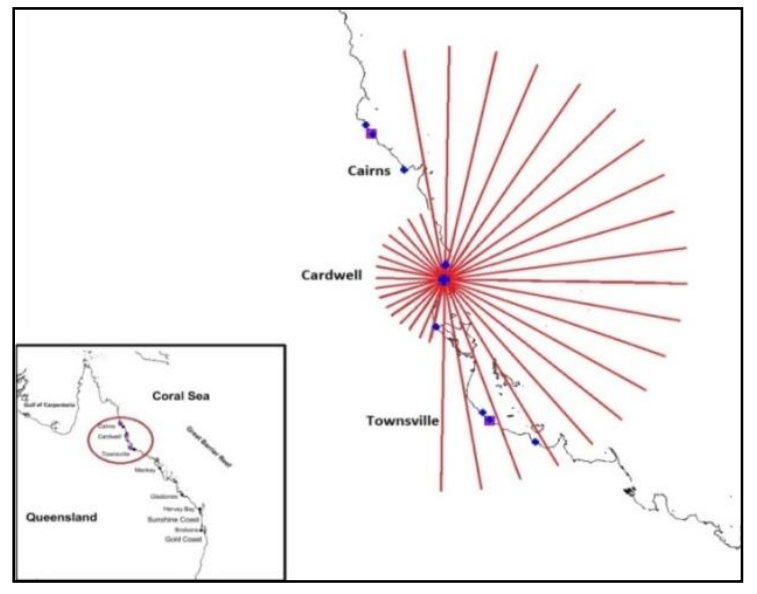

Figure 1 Location of the landfall points (pink squares) for Experiment 1 showing representative cyclone tracks through Cardwell showing the range of angles of approach considered shown in red. The extracted model output points are shown as blue diamonds. 
Faivre et. Al, Queensland Storm Surge Forecasting Model Design Using Sensitivity Analysis

sensitivity to second order processes such as the tide and wave interaction, as identified for the TC Yasi case study in Burston (2014).

The test synthetic cyclones in each experimental set described in the following sections maintained constant parameters along straight line tracks. Landfall locations for the test cyclones have been selected as $45 \mathrm{~km}$ north of Cairns and Townsville and $50 \mathrm{~km}$ north of Cardwell, respectively. For the purposes of this sensitivity test, second order processes such as dynamic tide, waves and inundation have been neglected, allowing isolation of the effects of the TC parameters on surge.

\subsection{Storm surge hydrodynamic model - MIKE21 FM}

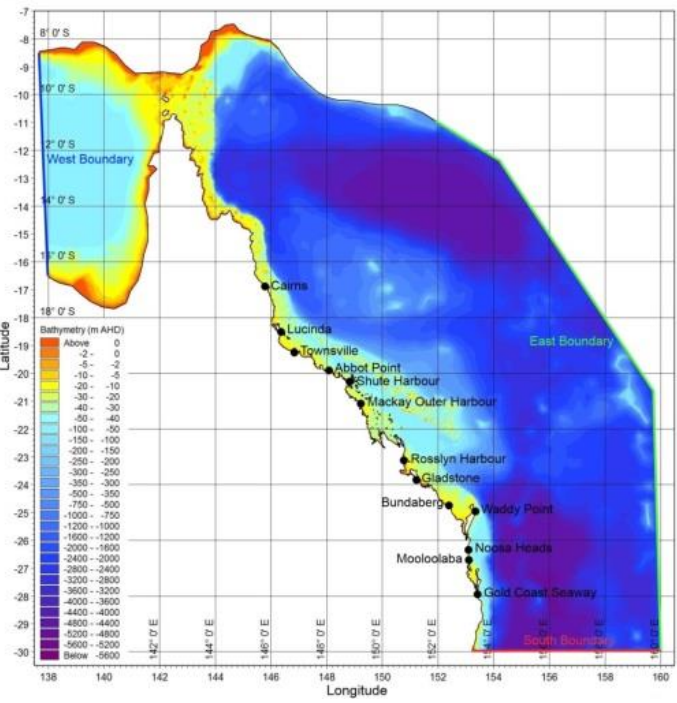

The hydrodynamic Coral Sea model was established for numerical modelling of the astronomical tide and storm surge using MIKE21 Hydrodynamic (HD) Flexible Mesh (FM) module. The model consists of $\sim 87000$ elements

Figure 2 The Coral Sea Hydrodynamic model extent, bathymetry boundaries and calibration sites.

with arc lengths that range from 1-2 km in nearshore, $2 \mathrm{~km}$ over the GBR and up to $45 \mathrm{~km}$ offshore (Burston and Symonds, 2013).

The model bathymetry is the best available as sourced from multiple local, state, and federal agencies and industry, and adjusted to AHD (Figure 2). The land elevation was obtained from 1-m LiDAR data supplied by the Queensland State government The model has been calibrated to the astronomical tide for 13 measurement sites from the Gold Coast Seaway (27.95 ${ }^{\circ} \mathrm{S}$ ) to Cooktown (15.45 ${ }^{\circ} \mathrm{S}$ ) (Burston and Symonds, 2013). The setup of the hydrodynamic model is outlined in Table 1 (Burston and Symonds, 2013).

Table 1. MIKE21 Coral Sea hydrodynamic model parameters for simulation of tropical cyclones.

\begin{tabular}{|l|l|}
\hline Model Parameter & Setting \\
\hline Maximum Time Step & $30 \mathrm{sec}$ \\
\hline Numerical Solution Type & First-order \\
\hline Wetting and Drying & Included \\
\hline Density & Barotropic \\
\hline Eddy Viscosity & Constant Smagorinsky formulation \\
\hline Bed Friction & Mannings M = 30 \\
\hline Coriolis Effect & Spatially-varying \\
\hline Initial Water Level Condition & Constant MSL (unless stated) \\
\hline Drag Coefficient, $C_{d}$ & $\begin{array}{l}\text { Based on Wu (1982): Linearly varying between } 1.255 \mathrm{e}^{-3} \text { and } 2.2425 \mathrm{e}^{-3} \text { for } \\
\text { wind speeds between 7 and } 25 \mathrm{~m} \mathrm{~s}^{-1} \text {. Capped above } 25 \mathrm{~m} \mathrm{~s}^{-1} .\end{array}$ \\
\hline
\end{tabular}

\subsection{Wind set-up}

The single vortex cyclonic pressure and wind profile model of Holland et al. (2010) was applied to generate the forcing for the hydrodynamic model. This model provides an update to the Holland (1980) model by allowing spatial 'stretching' of the wind field to match wind speed observations at fixed points. This wind model is applied to the surface wind directly with use of a scaling factor, $B s$, and requires iterative estimation of the exponent term. It has advantages in replicating the observed thickening of the tails of the wind speed profile in comparison with Holland's (1980) model and also reduces the sensitivity of the outer wind profile to RMW (Burston 2013).

\section{RESULTS}

\subsection{Cyclone angle of approach}

Figure 3 shows the resultant variation in peak storm surge magnitude with the variation in angle of approach for Cairns, Cardwell and Townsville. The peak storm surge is strongly sensitive to the angle of approach of the cyclone, especially for the output point located at the southern radius of maximum winds from the 
landfall location. Differences in peak surge of almost $3 \mathrm{~m}$ and $2 \mathrm{~m}$ between NE and SE angles of approach at Cairns are observed for locations $10 \mathrm{~km}$ north and $45 \mathrm{~km}$ south of landfall, respectively. Tropical cyclones that make landfall with a big angle or perpendicular to the coast are likely to produce higher surge levels because as the cyclone approaches the coast areas the left-forward quadrant of the storm would receive the heaviest thunderstorm activity, since the rain bands would be feeding off the moist oceanic air (Nelson, 2014). Considering that the most significant storm surge generation occurs when the cyclone is over shallow area, the difference in surge computed for the different angle of approach are due to the bathymetry. Local topography, bays, headlands and offshore islands can amplify the storm surge. The average water level difference between adjacent angles of approach at $10^{\circ}$ increments is $0.20 \mathrm{~m}$ for Cairns, $0.30 \mathrm{~m}$ for Cardwell and $0.20 \mathrm{~m}$ for Townsville. $10^{\circ}$ spacing is the minimum required in order to maintain maximum errors of less than $0.30 \mathrm{~m}$ in the peak modelled surge, and even finer increments in angle of approach could be considered given larger maximum differences.

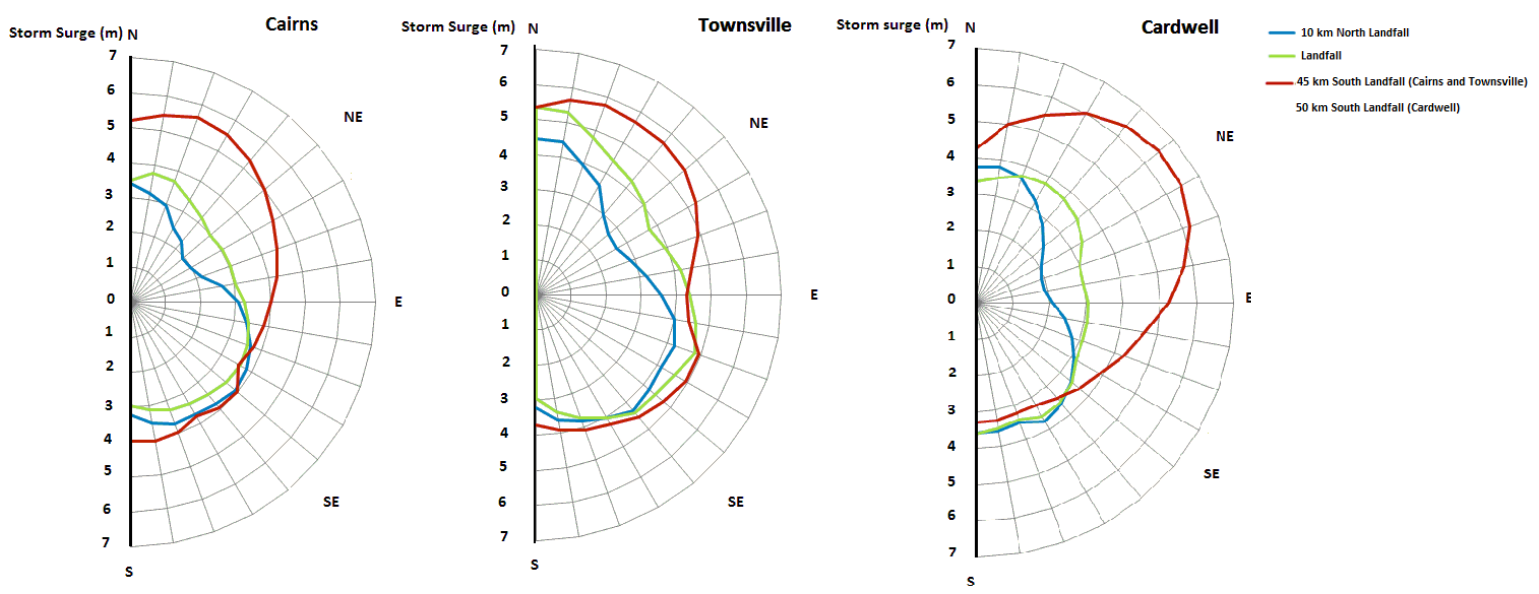

Figure 3. Comparison of peak storm surge magnitude with variable angle of approach for cyclones making landfall $45 \mathrm{~km}$ north of Cairns (left) and Townsville (centre) and $50 \mathrm{~km}$ north of Cardwell (right). (Pc $=900$ $\mathrm{hPa}$, Forward Speed $=10 \mathrm{~m} / \mathrm{s}, \mathrm{RMW}=40 \mathrm{~km}$ ).

\subsection{Cyclone forward speed}

The results in Figure 4 show that peak storm surge is highly sensitive to cyclone forward speed and the relationship between forward speed and peak surge is highly variable, location specific, likely dependent on the local bathymetric setting, and sensitive to the angle of approach These results preclude the use of a simplified relationship to characterise how peak surge may vary with forward speed and instead indicates that simulation of a full set of scenarios is required for ensemble TC storm surge modelling. A requirement for an increment of a maximum of $2 \mathrm{~m} / \mathrm{s}$ in the forward speed for use in ensemble tropical cyclone storm surge modelling is necessary in order to maintain average errors of less than $0.50 \mathrm{~m}$ in the peak modelled surge, although this threshold can be breached for specific cases.

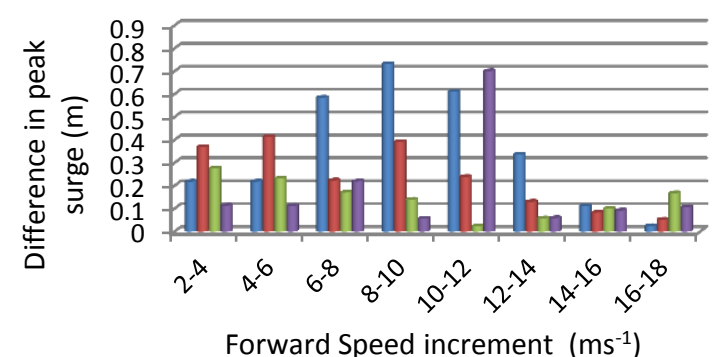

Forward Speed increment $\left(\mathrm{ms}^{-1}\right)$

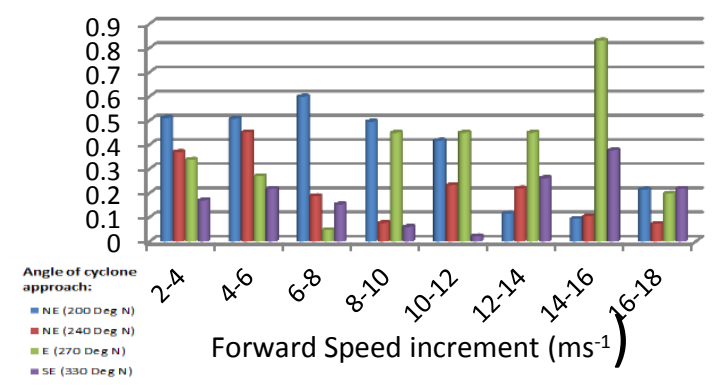

Figure 4. Difference in peak storm surge between adjacent forward speed values for cyclones making landfall $45 \mathrm{~km}$ north of Cairns (left) and Townsville (right) for the range of forward speeds between 2 and 18 $\mathrm{m} / \mathrm{s}$ in $2 \mathrm{~m} / \mathrm{s}$ increments. Results extracted $45 \mathrm{~km}$ south of the landfall location. 
Faivre et. Al, Queensland Storm Surge Forecasting Model Design Using Sensitivity Analysis

\subsection{Cyclone Intensity}

As expected, the modelled peak storm surge was found to decreases with increasing central pressure with a second order polynomial function providing excellent fit (Figure 5). Three values of central pressure (895, 950 and $1000 \mathrm{hPa}$ ) could be used to fit the peak storm surge variation with a high degree of accuracy for each specific combination of cyclone landfall location, angle of approach, RMW and forward speed. The absolute error between the modelled peak surge and peak storm surge estimated with the polynomial function is less than $10 \%$ for all Pc values and less than 5\% for Pc values lower than $990 \mathrm{hPa}$. Further details of this analysis are reported in Burston and Faivre (2014).

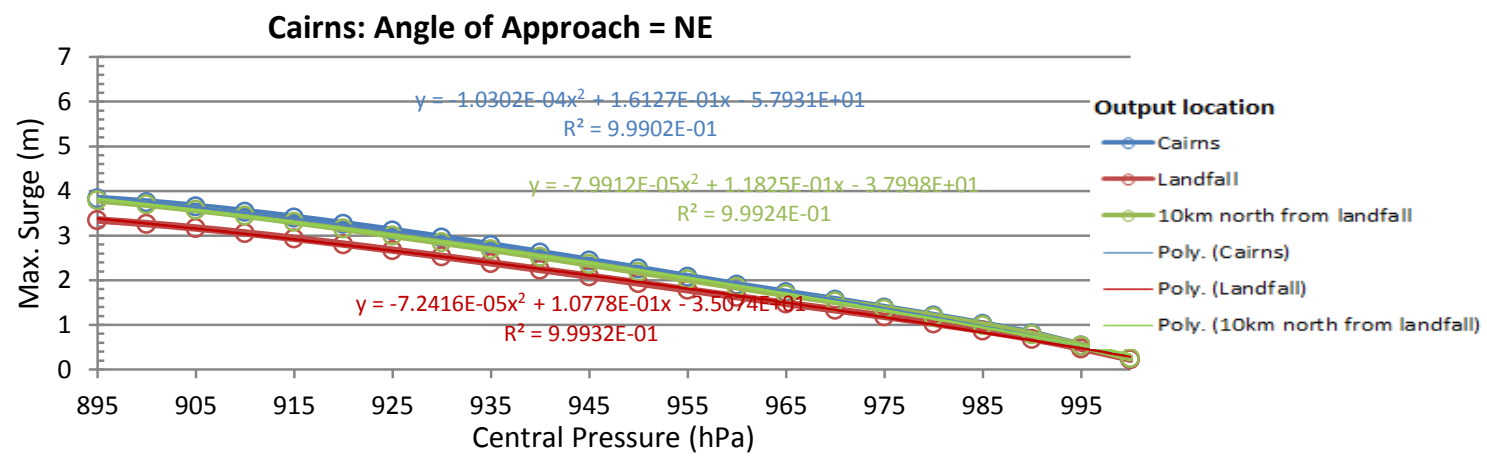

Figure 5 Variation of peak storm surge magnitude with central pressure for a cyclone making landfall 45 $\mathrm{km}$ north of Cairns for three output sites: at Cairns, at the point of landfall and at $10 \mathrm{~km}$ north of landfall for angles of approach from the northeast.

\subsection{Radius of maximum winds}

We modelled storm surge for a TC making landfall $45 \mathrm{~km}$ north of Cardwell, at an increment of $1 \mathrm{~km}$ for RMW between 10 and $30 \mathrm{~km}$. The results show that the peak storm surge is highly sensitive to RMW, for example, a variation of $20 \mathrm{~km}$ in RMW can change the simulated peak surge by $3.3 \mathrm{~m}$. (Figure 6). The maximum peak storm surge difference between two adjacent RMW values were $0.24 \mathrm{~m}$ and $0.48 \mathrm{~m}$ for an increment of $1 \mathrm{~km}$ and $2 \mathrm{~km}$ for RMW, respectively. The initial results indicated that using $5 \mathrm{~km}$ discrete increments in RMW would not capture the required accuracy in peak storm surge and a third-order polynomial fit using 5 RMW values could be appropriate as shown in Figure 6. Absolute errors between the estimates using this relationship and modelled peak surge for Cardwell are found to be less than $5 \%$. This experiment was then also conducted for Cairns and Townsville using the same storm central pressure (930 $\mathrm{hPa}$ ) as the experiment for Cardwell.

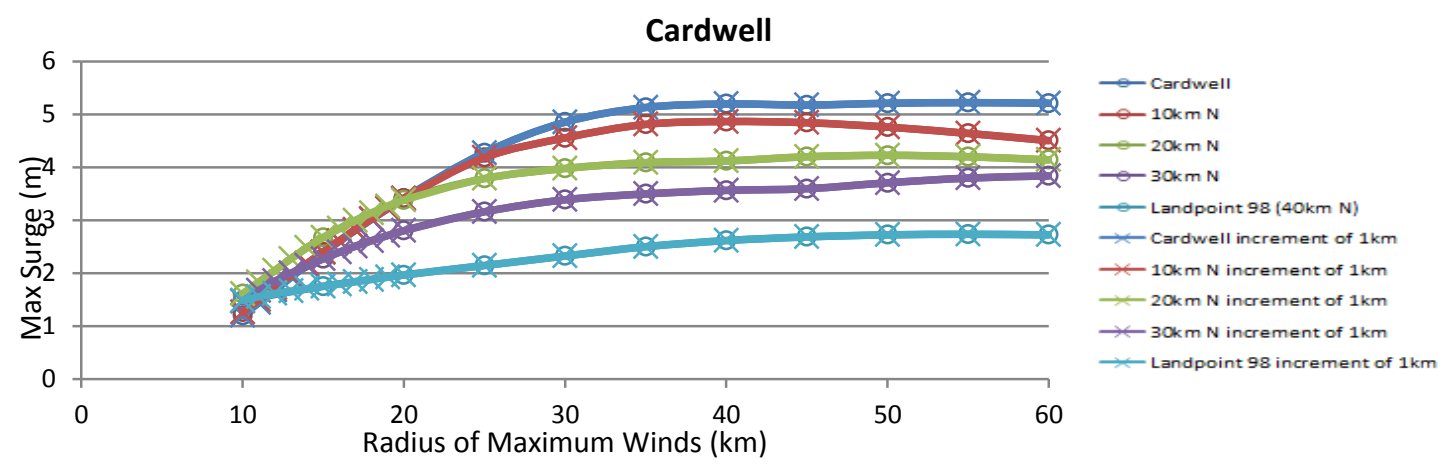

Figure 6. Comparison of peak storm surge magnitude at a range of output points for different radius of maximum winds for a cyclone making landfall $45 \mathrm{~km}$ north of Cardwell: Pc $=930 \mathrm{hPa}$, Forward Speed $=10 \mathrm{~m} / \mathrm{s}$, angle of approach $=240^{\circ} \mathrm{N}$. 


\subsection{Cyclone inflow angle}

The modelled peak storm surge was found to have limited sensitivity to the inflow angle for the case study investigated (Figure 7), and a constant value of $\beta=25^{\circ}$ for cyclone wind field beyond the RMW as applied by Harper et al. (2001) is appropriate for the Coral Sea region.

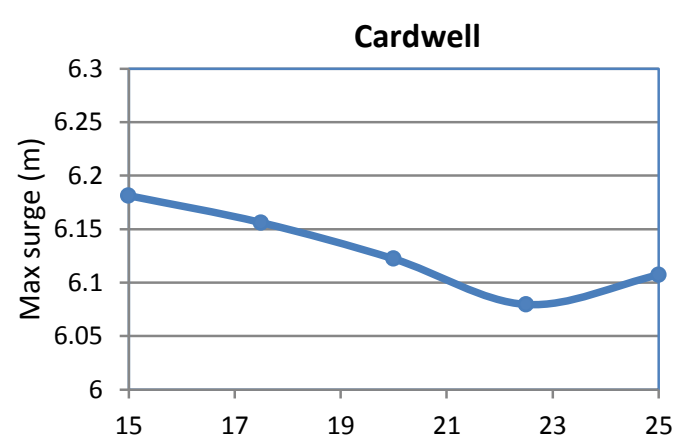

Figure 7 Comparison of the peak storm surge in Cardwell for different inflow angles for a case study TC making landfall at $45 \mathrm{~km}$ north of Cardwell. Pc=900 hPa, RMW $=40 \mathrm{~km}$, forward speed $=10 \mathrm{~m} / \mathrm{s}$, angle of approach $=240^{\circ} \mathrm{N}$

As a result of these experiments, we establish the size of the pre-simulated database required to capture the range of cyclonic events producing storm surge for North Queensland to be 2565 simulations per landfall point, giving a total of 664335 storm surge scenarios for landfall locations between Cooktown and the Whitsundays. For real-time ensemble modelling, we suggest the same spacing between cyclone parameters for ensemble formation. The model performance in terms of simulation time varies with number of computer cores. For the optimized Coral Sea tidal model, it was found that one day simulation take 130 s with 16 cores and runs in $72 \mathrm{~s}$ with 32 cores. To complete the pre-required database high performance computing facilities are required.

This research could be extended to cover all Queensland such as the Gulf of Carpentaria and South of Queensland and additional TC directions coming from the East and North East sides could also be integrated to the pre-simulated database. 
Faivre et. Al, Queensland Storm Surge Forecasting Model Design Using Sensitivity Analysis

Table 2. Summary of the sensitivity testing experiments defining the recommended values or spacing for various cyclone parameters and the resulting number of scenarios necessary to complete a full ensemble set for North Queensland.

\begin{tabular}{|l|l|l|}
\hline Parameter & Recommended Spacing / Values & Number of scenarios \\
\hline Forward angle & 10 degrees & $\begin{array}{l}19 \text { (for cyclones making landfall from } \\
\text { North to South) }\end{array}$ \\
\hline Landfall location & $5 \mathrm{~km}$ & 259 (from Cooktown to Whitsundays) \\
\hline Pc & $50 \mathrm{hPa}$ & 3 \\
\hline RMW & $\begin{array}{l}\text { Values: 10, 15, 25, 35, 60 km } \\
\text { combined with third order } \\
\text { polynomial function) }\end{array}$ & 5 \\
\hline Forward speed & $2 \mathrm{~m} / \mathrm{s}$ & 9 (from 2 to $18 \mathrm{~m} / \mathrm{s})$ \\
\hline Inflow angle & $\begin{array}{l}\text { Constant value of 25 for outer } \\
\text { cyclone }\end{array}$ & 1 \\
\hline Total no. scenarios for North Qld: & 664335 \\
\hline
\end{tabular}

\section{ACKNOWLEDGMENT}

This research project has been funded by Queensland State Government through the Department of Science, Innovation, IT and the Arts (DSITIA) and partner organisations: Griffith University, Queensland Fire and Emergency Services (QFES, DHI Water and Environment Pty Ltd and Queensland Cyber Infrastructure Foundation (QCIF).

\section{REFERENCES}

Burston, J.M. (2013) Coral Sea Wind Field and Storm Surge Validation Report. Griffith Centre for Coastal Management Research Report No. 146.

Burston, J.M. (2014). Storm Surge Modelling for Emergency Response Management in Queensland: Final. Project Report. Griffith Centre for Coastal Management Research Report.

Burston, J.M. and Faivre, G.S..(2014). Coral Sea Storm Surge Model, Sensitivity Analysis. Griffith Centre for Coastal Management Research Report No. 166.

Burston, J.M. and Symonds, A.M. (2013a). Coral Sea Tidal and Storm Surge Hydrodynamic Model Validation Report. Griffith Centre for Coastal Management Research Report No. 147.

Harper, B., Hardy, T., Mason, L., Bode, L., Young, I., and Nielsen, P. (2001). Queensland climate change and community vulnerability to tropical cyclones, ocean hazards assessment. Stage 1 report. Department of Natural Resources and Mines, Queensland, Brisbane, Australia.

Holland G.J. (1980) An analytic model of the wind and pressure profiles in hurricanes. Monthly Weather Review, 108, 1212-1218.

Holland G.J. Belanger J.I. Fritz A. (2010) A revised model for radial profiles of hurricane winds. Monthly Weather Review, 138, 4393-4401.

Nelson, S.A.(2014). Tropical Cyclones (Hurricanes). Tulane University, Tide-1220.

Wu, J. (1982) Wind stress coefficients over sea surface from sea breeze to hurricane. Journal of Geophysical Research, 87, 9704-9706. 